\title{
Fracture Surface Fractal Dimension and Its Relationship with the Impact Strength of the PP/Diatomite composites
}

\author{
Chen LIU $^{1, a}$, Chengbao WU ${ }^{1, b^{*}}$, Jing WEI ${ }^{1, c}$, Zhenghua $\mathrm{CHEN}^{2, \mathrm{~d}}$ \\ ${ }^{1}$ School of Aircraft Maintenance and Engineering, Guangzhou Civil Aviation College, Guangzhou \\ 510430, P.R. China \\ ${ }^{2}$ Maintenance Engineering Department, Guangzhou Baiyun International Airport Ground Servicing \\ LTD. Company, Guangzhou, 510470, P.R. China \\ aliuchen@caac.net, ’wuchengbao@caac.net, 'weijing@caac.net, 'steffens@163.com
}

Keywords: Polypropylene, diatomite, composite, fracture fractal dimension, impact strength

\begin{abstract}
The surface of diatomite particles was treated by a silane coupling agent, and the diatomite filled polypropylene (PP) composites with a volume fraction range of the filler from 0 to $15 \%$ were prepared by means of melt blending in a twin-screw extruder. The impact strength of the composites was measured at room temperature. The impact fracture surface fractal dimensions of the composite systems were measured using a projective-covering method, and a relationship between the fractal dimension and the impact strength of the composites was investigated. The results showed that the measured surface fractal dimension of the specimens was in a range from 2.4754 to 2.5230 , and the fracture surface fractal dimension is an exponential function of the impact strength of PP/Diatomite composites.
\end{abstract}

\section{Introduction}

Polypropylene (PP) is extensively used in the automobile, household goods, packaging and electronic appliance properties applications due to its good performance and processing properties as well as low cost. However, its application is somewhat limited due to its high shrinkage rate, low modulus, and brittle and relatively poor impact resistance at room temperature, especially under extreme conditions such as low temperatures or high strain rates. Therefore, how to improve the dimensional stability and mechanical properties is extensively paid attention. In polymer industry, the modified measures such as the copolymerization [1], blending [2], filling [3], crosslinking [4] and grafting method [5] were normal methods used to manufacture products and meet the requirement of product performance. In general, the stiffness and dimensional stability of PP are improved significantly by filling with rigid inorganic particles which are widely used in industry, such as calcium carbonate $\left(\mathrm{CaCO}_{3}\right)$ [3], talcum powder[6], glass bead (GB)[7], hollow glass bead(HGB)[8], and so on.

Diatomite is a kind of silicate material. It is a nonmetal deposit that it is produced from the remains of diatoms living in ocean or lakes by action in natural circumstances. Diatomite has some properties such as good stability and dispersive property, acid-proof and heatproof, low density, wear proof, large surface area and high value of absorbing oil, and so on [9]. It is a new kind of filler or reinforcer extensively used in polymer composites, coat and paint, catalyst carrier, adsorbent carrier, surface activator, etc. Recently, diatomite is used extensively more and more in sound materials, construct materials and heat insulation materials $[9,10]$.

More recently, the authors [11] researched the tensile properties of glass bead-filled low density polyethylene composites, and proposed fractal model of tensile fracture surfaces for 
particulate-filled polymer composites. However, there have been few studies on the impact fracture toughness and its mechanisms of diatomite-filled polymer composites. The objective in this paper is to study the fractal character of impact fracture surface of PP/Diatomite composites based on the scanning electron microscopy (SEM) image of impact fracture and the relationship between the fractal dimension of impact fracture surface calculated by the projective-covering method and the impact strength of PP/Diatomite composites.

\section{Experimental}

Materials. An injection grade of PP with trade mark of CJS-700, supplied by Guangzhou petrochemical Co. Ltd in China was used as the matrix resin, the density and melt flow index $\left(230^{\circ} \mathrm{C}, 2.16 \mathrm{~kg}\right)$ of the resin were $0.91 \mathrm{~g} / \mathrm{cm} 3$ and $12 \mathrm{~g} / 10 \mathrm{~min}$, respectively.

Two kinds of diatomite with different size distribution used as the fillers in this work were supplied by Davidart Chemical Co. Ltd. (Guangzhou, China). The mean diameters of the fillers were 5, and $13 \mu \mathrm{m}$, and the density was $0.230 \mathrm{~g} / \mathrm{cm}^{3}$, the fillers were called respectively as 700 and 281 . The surface of the fillers was pretreated with a silane coupling agent by the supplier. The particle size of the fillers was measured by means of a laser size instrument (Model LS-C (I)) supplied by Omik Co. Ltd in Zhuhai city, China.

Sample preparation. Before mixing, PP and diatomite were dried in an oven at $90^{\circ} \mathrm{C}$ for 4 hours and then cooled down to room temperature. The materials were stored in a desiccator prior to processing. After mixing simply, the PP resin and the diatomite with different proportions were compounded in a twin-screw extruder. The blending was conducted in a temperature range of $160-230^{\circ} \mathrm{C}$ and the screw speed of $25 \mathrm{r} / \mathrm{min}$, and then the extrudate was granulated to produce the composites. The volume fraction of the diatomite was $0,5,10,15 \%$. The composites were called as $\mathrm{PP} / 281$, PP/700, respectively. The specimens for Izod impact tests were modeled by using an injection-molding in temperature range from 160 to $240^{\circ} \mathrm{C}$ after drying the composites. The geometry of the impact specimens was made according with ASTM D256-93 standards, respectively.

Apparatus and methodology. The V-notched Izod impact tests of the composites were carried out by means of a Ceast pendulum impact tester (Ceast Code 6545/000). The impact tests were conducted according to ASTM D256-93 standard. The impact strength of the specimens was measured also at room temperature.

A SEM (Hitachi S-3700 field emission SEM) was used to observe the impact fracture morphology of PP/Diatomite composites. The specimens for SEM observation were prepared from impact experiments; the fracture surfaces of impact specimens were sputter-coated with a thin gold layer before examination.

\section{Results and Discussion}

Impact strength and fracture surface morphology. The values of the narrow-side impact strength for PP/Diatomite composites are listed in Table 1.

It can be seen from Table 1 that the impact strength of the composites increases with an increase of volume fraction of the filler when the volume fraction was less than $10 \%$. When the filler volume fraction is larger than $10 \%$, the impact strength of the composites decreases somewhat with increasing the filler volume fraction. In addition, the impact strength of the composites is much larger than that of the neat PP even the volume fraction of the filler reaches $15 \%$. 
Table 1 Narrow-side impact strength of PP/diatomite composites

\begin{tabular}{|c|c|c|c|c|}
\hline$\phi_{f}(\%)$ & 0 & 5 & 10 & 15 \\
\hline PP281 system $\sigma_{I}\left(k J / m^{2}\right)$ & 11.3281 & 12.6953 & 13.0859 & 12.1094 \\
\hline PP700 system $\sigma_{I}\left(\mathrm{~kJ} / \mathrm{m}^{2}\right)$ & 11.3281 & 11.7188 & 12.1094 & 11.9141 \\
\hline
\end{tabular}

Fig. 1 shows the SEM image of impact fracture surface for the neat PP.

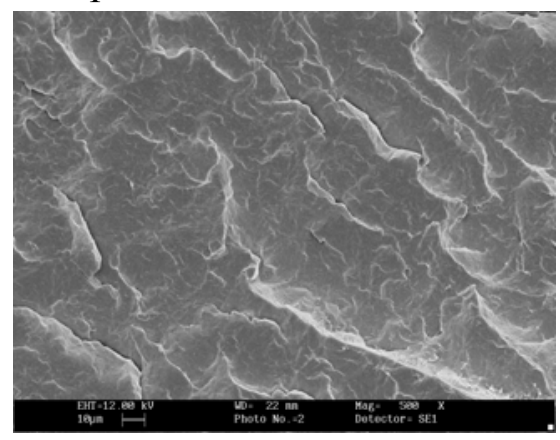

Fig.1 The impact fracture SEM image of neat PP

It may observe that the fracture surface looks like waves. It means that the neat PP specimen break relatively fast due to quick development of micro-crack under impact load, leading to low impact strength (see Table 1).

Fig.2 and Fig.3 display respectively the SEM images of PP/281 and PP/700 systems with different volume fraction of the fillers.

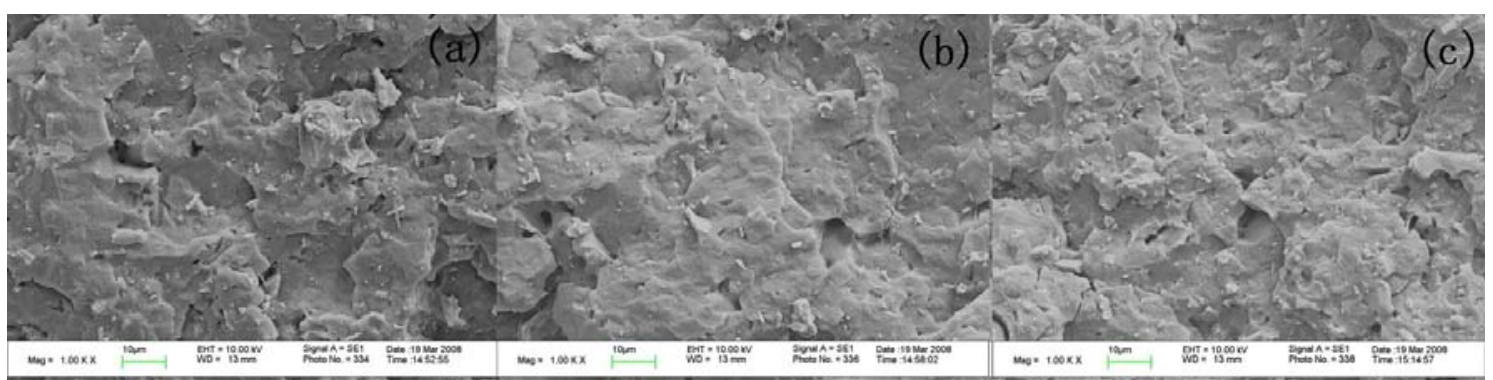

Fig. 2 The impact fracture SEM images of PP/281 system with different volume fraction of the fillers: (a) $5 \%$, (b) $10 \%$, (c) $15 \%$.

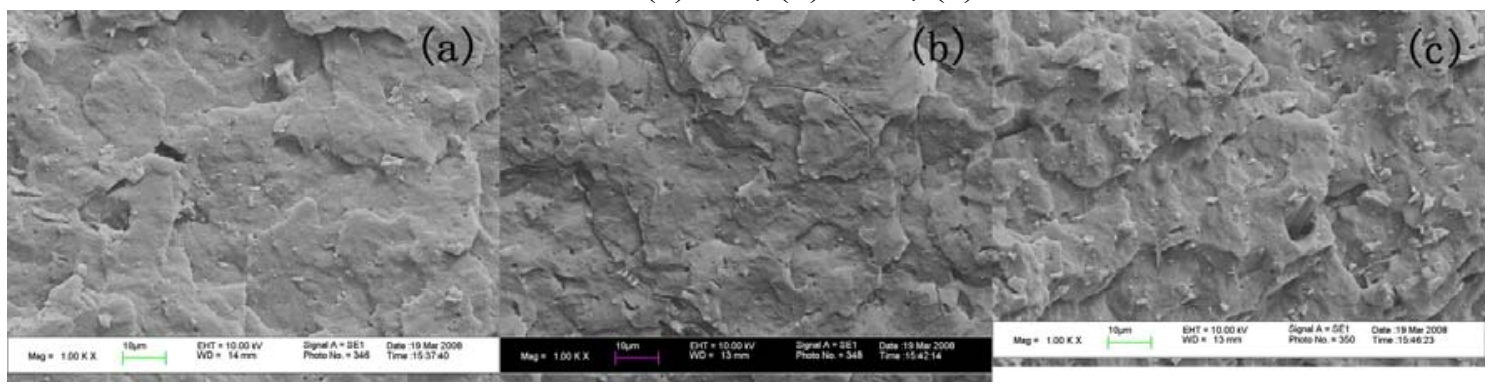

Fig.3 The impact fracture SEM images of PP/700 system with different volume fraction of the fillers: (a) $5 \%$, (b) $10 \%$, (c) $15 \%$.

It can be seen from Fig. 2 that there are a number of small platforms on the impact fracture surface, and the variation of the shape and size of these small platforms do not evidently with an addition of the filler concentration.

Similarly, we can find from Fig. 3 that there are a number of small platforms on the fracture surface, and the shape and size of these small platforms change slightly with an addition of the filler concentration. In general, the matrix around the inclusions will yield first under impact load due to 
stress concentration to generate plastically deformation and form small platforms on the fracture surface. These small platforms will absorb relevant impact deformation energy or fracture energy, leading to improving obviously the impact fracture toughness of the composite systems (see Table 1).

Calculation of Ds of impact fracture surface. As stated above, the morphology of impact fracture surface of polymer composite depends, to great degree, upon the particle size, volume fraction of filler, and the dispersion of the particles in matrix resin and the characteristics of the matrix resin. Before calculating the $D_{s}$ of the impact fracture surface, the original SEM images should be input a computer firstly. Then, the original images were changed to digital image by image process software Photoshop. Lastly, the program compiled by $\mathrm{VC}++$ based on the calculation principle[12] of $D_{s}$ was used to calculate the $D_{s}$ of impact fracture surface. The calculating curves for $\mathrm{PP} / 281$ and PP/700 systems are shown in Fig.4.

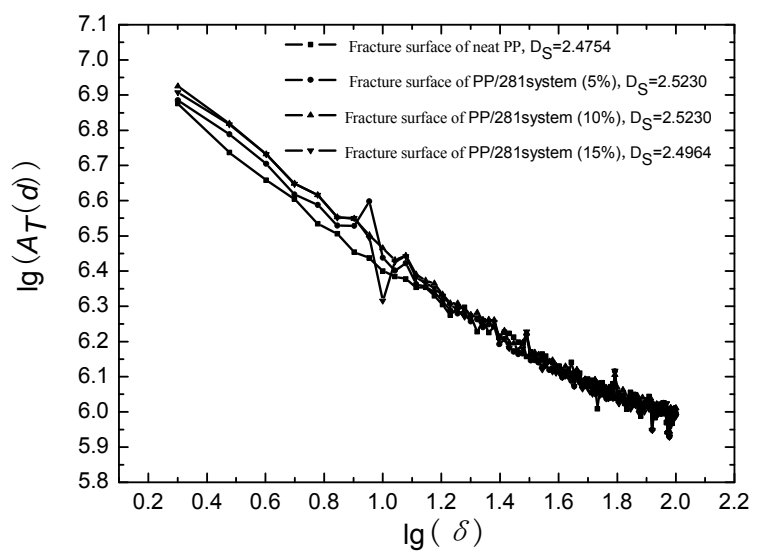

(a)

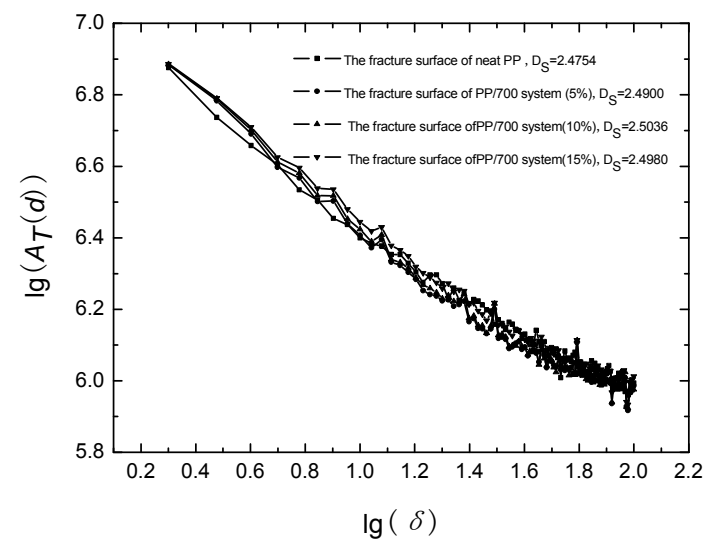

(b)

Fig.4 The $\lg (\delta)$ vs $\lg \left(A_{T}(\delta)\right)$ curves of PP/281 and PP/700 systems: (a) PP/281 system, (b) $\mathrm{PP} / 700$ system

It can be seen from Fig. 4 that the $\lg (\delta) \sim \lg (A T(\delta))$ curves of $\mathrm{PP} / 281$ and $\mathrm{PP} / 700$ systems are roughly linear. Therefore, the data may be fitted by means of a linear regression analysis method, and the regression results are listed in Table 2.

Table 2 Fracture surface fractal dimension of PP/diatomite composites

\begin{tabular}{cccc}
\hline $\begin{array}{c}\text { Materia } \\
\text { 1 system }\end{array}$ & $\begin{array}{c}\text { Volume } \\
\text { fraction } \\
(\%)\end{array}$ & $\begin{array}{c}\text { correlatio } \\
\text { n coefficient } \\
(R)\end{array}$ & $\begin{array}{c}\text { Surface } \\
\text { fractal } \\
\text { dimension } \\
\left(D_{S}\right)\end{array}$ \\
\hline $\mathrm{PP}$ & 0 & 0.9884 & 2.4754 \\
$\mathrm{PP} / 281$ & 5 & 0.9817 & 2.5114 \\
$\mathrm{PP} / 281$ & 10 & 0.9844 & 2.5230 \\
$\mathrm{PP} / 281$ & 15 & 0.9811 & 2.4964 \\
$\mathrm{PP} / 700$ & 5 & 0.9791 & 2.4900 \\
$\mathrm{PP} / 700$ & 10 & 0.9814 & 2.5036 \\
$\mathrm{PP} / 700$ & 15 & 0.9862 & 2.4980 \\
\hline
\end{tabular}

Relationship between Ds and impact strength. Fig. 5 shows a relationship between the Ds and the impact strength of the PP/Diatomite composites. 


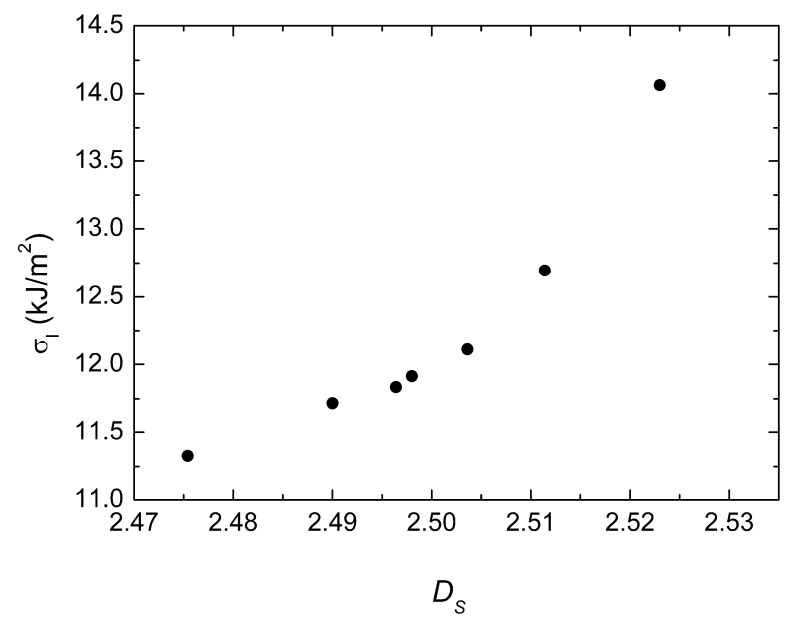

Fig.5 $\sigma_{I}$ verse $D_{S}$

It can be seen from Fig.5 that the impact strength of the PP/Diatomite composite increases non-linearly with increasing $D_{s}$ of impact fracture surface. In order to characterize quantitatively the relationship between $D_{s}$ and the impact strength of PP/Diatomite composites, we took a natural logarithmic of impact strength of PP/Diatomite composite, and potted it versus $D_{s}$. to fit the data between $\ln \sigma_{I}$ and $D_{s}$ by least square method, we can find the relationship between them can be described by following equation:

$\ln \sigma_{I}=-0.84+4.3632 D_{s}$

That is

$\sigma_{I}=0.00024 \mathrm{e}^{4.3632 \mathrm{D}_{\mathrm{s}}}$

The correlation coefficient of the linear regression analysis (Equ.1) is 0.9338. As discussed above, the strong correlation coefficient indicates that the relationship between the fractal dimension and impact strength of the composites obeys roughly an exponential function.

\section{Summary}

The narrow-side impact strength of PP/Diatomite composite at room temperature increased with the increasing content of filler when the volume fraction was less than $10 \%$, and then decreased slightly when the volume fraction was larger than $10 \%$ for both $\mathrm{PP} / 281$ system and $\mathrm{PP} / 700$ system. The impact strength of PP/281 system was somewhat larger than that of PP/700 system.

The coarse degree of the impact fracture morphology of various PP/Diatomite composite systems was different, and the surface fractal dimension can be used to characterize the coarse degree quantitatively. The fractal dimension of the impact fracture surface of PP/Diatomite composites was in the range from 2.4754 to 2.5230 , and the correlation coefficients were larger than 0.97, this strong correlation coefficient indicated that the impact fracture was fractal. The further study showed that the fracture surface fractal dimension is an exponential function of the impact strength of PP/Diatomite composites. 


\section{References}

[1] F. Machado, E.L. Lim, J.C. Pinto, et al., In situ preparation of polypropylene/1-butene alloys using a MgCl2-supported Ziegler-Natta catalyst, Eur. Polym. J., 44(2008)1130-1139.

[2] F.Y. Yu, H.B. Zhang, H. Zheng, et al., Experimental study of flow-induced crystallization in the blends of isotactic polypropylene and poly (ethylene-co-octene), Eur. Polym. J., 44(2008) 79-86.

[3] K. Gorna, M. Vucak, F. Grohn, et al., Amorphous calcium carbonate in form of spherical nanosized particles and its application as fillers for polymers, Mater. Sci. Eng., 477(2008)217-225.

[4] R.D. Wu, X.L. Tong, A Study of cross-linking polystyrene rigid particles encapsulated with SBS toughing polypropylene, Poly. Mater. Sci. Eng., 21(2005)298-299.

[5] A. Okamura, T. Hagiwara, S. Yamagami, et al, Effective cell separation utilizing poly (N-Isopropylacrylamide)-grafted polypropylene membrane containing adsorbed antibody, J. Bio-Sci Bio-Eng., 105(2008)221-225.

[6] F. Stricker, M. Bruch, R. MLilhaupt, Mechanical and thermal properties of syndiotactic polypropylene filled with glass beads and talcum, Polym., 38(1997)5347-5353.

[7] W. Yang, Z.Y. Liu, G.F. Shan, et al, Study on the melt flow behavior of glass bead filled polypropylene, Polym. Test., 24(2005)490-497.

[8] J.Z. Liang, Impact fracture toughness of hollow glass bead-filled polypropylene composites, J. Mater. Sci., 42(2007)841-846.

[9] S.E. Tvanov, A.V. Belyakov, Diatomite and its applications, Glass Ceram., 65(2008)48-51.

[10] Z.S. Hong, , Y. Tateishi, J. Han, Experimental study of macro- and microbehavior of natural diatomite, J. Geo-Tech. Geo-Environ. Eng., 132 (2006)603-610.

[11] J.Z. Liang, C.B. Wu, A fractal model of tensile fracture surfaces for particulate-filled polymer composites, J. Appl. Polym. Sci., 109(2008)3763-3767.

[12] B. B. Mandelbrot, the Fractal Geometry of Nature, Freeman: New York, 1982. 